Article

\title{
USAPI USDM: Operational Drought Monitoring in the U.S.-Affiliated Pacific Islands
}

\author{
Richard R. Heim, Jr. ${ }^{1, *}$, Charles Guard ${ }^{2}$, Mark A. Lander ${ }^{3}$ and Brandon Bukunt ${ }^{4}$ \\ NOAA/NESDIS/National Centers for Environmental Information, Asheville, NC 28801, USA \\ Tropical Weather Sciences, Guam, GU 96910, USA; stychip@gmail.com \\ 3 Water \& Environmental Research Institute of the Western Pacific, University of Guam, Mangilao, GU 96913, \\ USA; mlander@uguam.uog.edu \\ 4 NOAA/National Weather Service Forecast Office, Guam, GU 96913, USA; brandon.bukunt@noaa.gov \\ * Correspondence: Richard.Heim@noaa.gov
}

Received: 14 April 2020; Accepted: 7 May 2020; Published: 12 May 2020

check for updates

\begin{abstract}
The U.S. Drought Monitor (USDM) has been the de facto operational drought monitoring product for the United States for the last two decades. For most of this time, its coverage included the 50 States and Puerto Rico. In 2019, coverage was expanded to include the U.S.-Affiliated Pacific Islands (USAPI). The geography, geomorphology, and climatology of the USAPI significantly differ from those of the mainland U.S. (CONUS) and they posed a unique challenge for the USDM authors. Following National Oceanic and Atmospheric Administration (NOAA) priorities for development of products in collaboration with users in what is termed "use-inspired science", NOAA agencies conducted several workshops to identify data and impacts relevant for, and develop drought monitoring criteria appropriate for, the USAPI. Once the criteria were identified and data processing systems were set up, the USAPI were included as part of the operational USDM drought monitoring beginning in March 2019. The drought monitoring criteria consist of weekly and monthly minimum precipitation thresholds for triggering drought, and they follow the USDM "convergence of evidence" methodology for determining the severity level (Dx) of the drought spell.
\end{abstract}

Keywords: drought; USDM; U.S.-Affiliated Pacific Islands (USAPI); U.S. Drought Monitor; monitoring; user-inspired science

\section{Introduction}

The U.S. Drought Monitor (USDM) was created in 1999 [1]. As its popularity grew and it became the trigger for many state drought plans and federal drought relief funds [2], the USDM became the de facto operational drought monitoring tool in the United States [3]. From 2000-2018, the USDM was analyzed for the 50 States and Puerto Rico. Beginning in 2019, the drought analysis was expanded in order to cover the U.S.-Affiliated Pacific Islands (USAPI) and the U.S. Virgin Islands (USVI). The USAPI include the U.S. territories Guam and American Samoa, the Commonwealth of the Northern Mariana Islands, and the free states of the Republic of Palau, the Federated States of Micronesia (FSM), and the Republic of the Marshall Islands (RMI). All of the USAPI, except American Samoa, are north of the Equator within the broad region of Oceania known as Micronesia.

Dozens of in situ and space-based drought indices and indicators are computed for the mainland U.S. (CONUS). These include such indices as the Standardized Precipitation Index (SPI), Palmer Drought Index, Evaporative Drought Demand Index, Vegetation Health Index (NDVI/VHI), Vegetation Drought Response Index (VegDRI), and many others. Drought indicators include snow water content for the western U.S., streamflow and groundwater measurements, soil moisture observations and models, crop condition, and many others. The data are most readily related to a USDM dryness (D0, 
abnormally dry) or drought (D1-D4, moderate to exceptional drought) category (Table 1) if they have a sufficiently long period of record that enables them to be converted into a historically-based percentile format. The indices and indicators are analyzed by the USDM author in a "convergence of evidence" approach to determine the USDM Dx category, the draft analyses are peer-reviewed by a cadre of local experts (currently over 400), and the final USDM map product is created while using ArcGIS tools.

Table 1. The U.S. Drought Monitor (USDM) classifies drought into four categories (D1-D4) and an abnormally dry category (D0) according to a percentile system, similar to the idea behind the Saffir-Simpson hurricane wind scale and Fujita tornado intensity scale, as noted in [1].

\begin{tabular}{cccc}
\hline Description & Category & Percentile & Recurrence Interval \\
\hline Abnormally Dry & D0 & $0.20-0.30$ & Once per 3 to 5 years \\
Moderate Drought & D1 & $0.10-0.20$ & Once per 5 to 10 years \\
Severe Drought & D2 & $0.05-0.10$ & Once per 10 to 20 years \\
Extreme Drought & D3 & $0.02-0.05$ & Once per 20 to 50 years \\
Exceptional & D4 & $0.00-0.02$ & Once per 50+ years \\
Drought & & & \\
\hline
\end{tabular}

Drought is a complex phenomenon that consists of several different types (meteorological, hydrological, agricultural, socioeconomic, ecosystem) that affect multiple sectors differently and act on multiple time and space scales [3]. A variety of drought indices and indicators is needed to describe these characteristics. The USDM "convergence of evidence" process depends on multiple indices and indicators reaching "consensus", or "converging", on a drought status or Dx category.

To repeat: the "convergence of evidence" approach is dependent on the availability of a large number of indices and indicators that can be converted into a percentile format to capture the temporal, spatial, and sectoral dimensions of drought. The data for these indices and indicators are readily available for the CONUS, being reasonably available for Alaska, Hawaii, and Puerto Rico, but not so readily available for the USAPI and USVI. The small number of available indices and indicators for the USAPI hinders the convergence of evidence process. The hydrology, climatology, and geography of the USAPI differ significantly from those of the CONUS in addition to limited drought monitoring data and a much smaller number of available drought indices and indicators. Section 3 describes the hydrology, climatology, and geography of the USAPI in detail, but two examples of the differences are discussed here: (1) much of the CONUS experiences large swings in temperature on seasonal and synoptic time scales, resulting in a changing evapotranspiration (ET) demand that can significantly impact drought. Droughts are generally slow to emerge and slow to recede, but short-term dryness accompanied by such excessive ET can lead to the rapid development of drought, or "flash drought" [1]. An ET-based index can capture these changes for the CONUS. The USAPI are tropical islands with warm temperatures year-round and consistently high evaporative demand, which render an ET-based index less useful, because ET is constant throughout the year. Since drought results from an imbalance between water supply (precipitation) and water demand (ET) [3], the constant ET demand in the USAPI means that the lack of precipitation for even relatively short periods of time can result in the rapid development of drought. (2) Most of the islands are small and separated by large expanses of ocean, which hinders the development of extensive water supply systems, like those on the CONUS, which can buttress the populace against the impacts of drought. The limited drought indicators, indices, and data, and the hydrological, climatological, and geographical differences require a slightly different approach for analyzing drought for the USAPI than for the CONUS (the USVI will not be further discussed in this paper).

In the development of new products, and improvement of existing products, to meet stakeholders' needs, the National Oceanic and Atmospheric Administration (NOAA) follows a "use-inspired science" philosophy that links climate tools and services to sector-specific users and requirements (e.g., [4]). This involves engaging with users and stakeholders through such processes as "participatory design" and "human-centered design" [5-10]. Recent examples of such engagement include Kruk et al. [11] and 
Bathke et al. [12]. Three meetings were held (August 2011, October 2012, August 2018) to engage users in the Pacific arena with the goal of determining available data, impacts, and appropriate processes in order to assess drought in the USAPI. This paper summarizes the results of these user engagements; the unique USAPI hydrological, climatological, and meteorological processes that are relevant to drought; and the system established for analyzing drought in the USAPI as part of the USDM process.

\section{The User-Engagement Workshops}

Two meetings were held in 2011 and 2012 by NOAA and University of Guam (UoG) personnel to assess data availability, hydrological and meteorological processes, and geographical characteristics that distinguish the USAPI from the CONUS. These meetings identified data and indicators that are appropriate for drought monitoring in the USAPI and established a corresponding drought monitoring process (these will be discussed in later sections). The first meeting was a series of daily gatherings held 9-19 August in Honolulu, Hawaii, and Guam between NOAA/National Weather Service (NWS) personnel at those locations and NOAA/National Centers for Environmental Information (NCEI) personnel, including USDM author Richard Heim. During this time, USDM training was provided for Pacific ENSO Applications Climate (PEAC) Center (now PEAC Services) personnel in Honolulu and NWS personnel in Guam; NWS weather, forecast, and drought monitoring activities unique to Hawaii and the USAPI were discussed; and, an approach was developed to incorporate USAPI drought monitoring into the USDM product (see later sections).

The 2012 meeting was held 29-31 October in Honolulu as a follow-up to the 2011 meeting. NWS and NCEI personnel established specific criteria and processes for the USAPI in the USDM environment. These included: (1) establishing the daily data base, daily data transmission, daily drought indicators, and operational schema for assessing drought conditions in the USAPI on a weekly basis and meshing that process into the monthly USAPI drought assessment process; (2) creating a drought classification rules base for the USAPI while using the daily data-based indicators and integration of the USAPI weekly drought assessment into the weekly USDM production schedule; (3) determining the best method for depicting USAPI drought conditions in the USDM map format; and, (4) identifying mechanisms for more systematically collecting drought (and other climate) impacts information from the USAPI and feeding the impacts information into the USAPI/USDM, PEAC newsletter, and Pacific Seasonal Outlook products, as well as strengthening the three-way relationship between these three products.

A workshop ("Drought in the USAPI-Impacts, Resilience, and Management") was held by the USGS National Climate Adaptation Science Center (NCASC) on 14-15 August 2018 in Honolulu to identify the key threats, challenges, and management solutions related to drought, as it impacts ecology, agriculture, water supply and distribution, and other key sectors in the USAPI. These were determined via prepared talks and interactive breakout sessions. The participants included federal personnel from the NWS, Department of the Interior Pacific Islands Climate Adaptation Science Center, U.S. Geological Survey, and U.S. Forest Service; Guam state offices; Universities of Guam and Hawaii; USAID; East-West Center; Desert Research Institute; and National Drought Mitigation Center [13]. The results of the workshop are summarized in a series of two-page reports that focus on impacts to water resources [14], agriculture [15], and ecosystems [16], and drought monitoring data needs and challenges [17] (see impact details below).

\section{The Nature of Drought in the USAPI}

Drought results from an imbalance between water supply and water demand [3]. The USAPI are tropical islands with warm temperatures year-round and consistent evapotranspiration (water demand, ET), so drought results from variations (deficiencies) in precipitation (water supply). The average annual rainfall at all USAPI sites exceeds $1778 \mathrm{~mm}$ [18], but the islands experience pronounced wet and dry seasons [19]. The climate drivers affecting precipitation are largely related to variations in the Inter-Tropical Convergence Zone (ITCZ) for Micronesia and South Pacific Convergence Zone (SPCZ) 
for American Samoa, and the El Niño/Southern Oscillation (ENSO). The trade winds, the North Pacific Subtropical High, and the proximal East Asian Monsoon and local Western North Pacific Monsoon (WNPM) systems strongly influence the weather and climate in Micronesia, while an eastern extension of the Australian Northwest Monsoon has some summer influence on the weather of American Samoa. The number, severity, and track of tropical cyclones also strongly influences precipitation in both regions [18,20]. The Madden-Julian Oscillation (MJO) can modulate tropical cyclone activity and, thus, affect month-to-month variation of rainfall. Based on meteorological data since World War II, the USAPI have experienced five major drought episodes in 1970, 1983, 1992, 1998, and 2016, as well as other more minor events [18].

The USAPI consist of many small islands (Guam, the largest, is only $549 \mathrm{~km}^{2}$ in size) spread across an expanse of Pacific Ocean as wide as the CONUS. They consist of two types: high islands and low islands. High islands have varied topography, mountains, and streams. Low islands are mostly atolls reaching two to three meters above sea level. Both can have fresh water aquifers. Food and water security are the most important aspects of drought for the USAPI due to their small size and relative isolation. Maintaining adequate freshwater supplies in the islands is of critical concern as demographic and climatic changes place stresses of uncertain magnitude on already fragile water resources. Populations on low-lying atoll islands are particularly vulnerable to freshwater-supply shortages and agricultural-crop losses during droughts [14]. The RMI is mostly composed of atolls, which exhibit rapid responses to drought conditions lasting more than several months [21], with a few isolated, relatively low solitary islands (e.g., Mejit, Kili, Jemo, Jabat). The northern atolls of the RMI lie in a sector that has exhibited an anomalous drying climate regime over the period 1954-2011 in comparison to surrounding areas [18,19]. Whereas drought is an episodic phenomenon in the Marianas, Carolines, and Samoa, it has become a nearly chronic condition in the northern RMI, resulting in the loss of mature native breadfruit and coconut trees [18].

Water resources in the USAPI include rainwater, groundwater, and intermittent or perennial streamflow. Municipal water-supply systems serve several of the more populated areas of high islands. In contrast, populations living in rural areas, particularly on low-lying atoll islands in the FSM and RMI, are dependent on groundwater from shallow wells or rain from private catchment systems [14]. The fresh water aquifers largely sit atop saline groundwater and, thus, are fresh water aquifer lenses. During droughts, fresh water aquifers thin, due to a lack of rain recharge from above and intrusion of the underlying salt water into the fresh water lens from below. On the less developed outer islands, there are no groundwater gauges, so they do not know that the lens is thinning until there is suddenly no usable water. Wells pumping this groundwater will slowly draw in salt water, broadening the transition zone that will reach a critical point; when that critical point is reached (no longer pumping freshwater, but now pumping saline (brackish) water), there is immediately no fresh drinking water and a life or death crisis occurs-the people have no water, so this drought impact can occur literally overnight (a "super flash drought").

Most of the high islands in the USAPI have largely impermeable surfaces comprised of weathered clays derived from chemical weathering of underlying dense basalts, such that, in most catchments, over 50 percent of the annual rainfall moves to the sea as runoff rather than recharging any underlying aquifers [18]. An exception is northern Guam, which is an elevated limestone plateau of high permeability with large subsurface aquifers $[18,20]$. High island groundwater lenses recharge better than low island groundwater lenses (they are helped by springs that are fed from the basalt rock); low island groundwater lenses drain faster. A drop in sea level commonly observed during El Niño will lower the groundwater level that could exacerbate the drought that often occurs during and after the El Niño peaks. The severity is usually much more an issue for low islands than for high (mountain) islands.

Water supply issues vary with type of island, but drought largely impacts drinking water supplies for all islands, as previously highlighted. For high islands, surface water sources, such as catchment level and reservoir levels, are important. Three high islands (Guam, Yap, and Palau) have reservoirs, 
but Guam suffers from an insufficient distribution system to move water from one part of the island to another. Free-flowing streams are often the sources that are used for drinking water; during droughts, streamflow stagnates and river water becomes unusable creating a potential health problem, especially at Pohnpei and Kosrae. In general, low islands do not have streams or reservoirs. Majuro and Kwajalein are low islands that have reservoirs, but these are man-made "tanks" containing rainwater harvested from the runways. Most islands (except for Guam) use catchments to catch and store rain water. High and low islands both rely on rainfall and groundwater wells for drinking water. In addition to unusable water causing health problems for people, drought-related stress can directly increase the mortality of plants and animals, or make them more vulnerable to predation and disease [16].

Agricultural impacts do not occur as they do on the mainland (CONUS). The population on the islands has grown so large on the main islands that much of the food for those islands has to be shipped in, but there is subsistence agriculture on most of the islands (breadfruit, taro, tapioca, banana, pandanas, coconut). The growing season for USAPI agriculture is year-round, although, on some islands with pronounced wet and dry seasons (such as Guam), most farming occurs during the dry season. There is some irrigation on large islands, such as Guam, but most agriculture is rain-fed. Lack of water (reduced rainfall) and salt water intrusion are hazards for crops. If a drought happens, it can begin rapidly, intensify rapidly, and end rapidly, but the agriculture may take eight to ten months to recover. In one instance (the 1997-1998 El Niño Drought), coconut production declined by 20\% from 1998-1999 and did not fully recover for over four years in the Federated States of Micronesia [15,18]. Crops respond to drought through reduced growth, increased mortality, susceptibility to pests/diseases, and reduction in overall production.

Dry periods usually follow El Niños and follow this typical scenario: The dryness starts during the late fall at Palau and spreads across all of Micronesia during January-April. Water resources can be greatly reduced. When the rains return, they typically follow this south-to-north progression: they arrive at Kosrae in April; Majuro, Pohnpei, Chuuk, and Palau in May; Yap and Kwajalein in June; Guam and Rota in July; and, Tinian and Saipan in August. Research summarized by Polhemus [18] identified three classes of El Niño events ("cold tongue", "mixed", and "warm pool" El Niños), with each having geographical differences in the areas experiencing dry weather.

Wildfires can be a drought indicator/impact, as drought will dry out vegetation, making it susceptible to burning. Thus, drought sets the conditions for wildfires to spread (they will not spread under wet conditions), but people start virtually all fires (not lightning). The most devastating combination is when you have very wet conditions with excessive fuel buildup during the year of El Niño onset, followed immediately by the extreme dryness that is typically observed in the first half of the post-peak year [16].

Typhoons may dump heavy rains (easily $250-500 \mathrm{~mm}$ ), but a tropical system (a single short-duration event with a lot of run-off) will not necessarily end a drought. The devastating winds accompanying the typhoon result in much dead vegetation, which can fuel fires. The typical pounding of Micronesia by all the typhoons of a typical strong El Niño year leaves a devastated wasteland of abundant dead-wood fuel for a few years. A worst case occurs when a typhoon hits in the dry season or during a drought, but more typically at the end of a busy El Niño year. The typhoon rains are largely run-off and dry weather rapidly returns. The general destruction of the forests by these typhoons leaves abundant flattened and compacted dead-wood fuels, which worsen the impact of the wildfires that occur in the dry months that follow.

\section{Operational Drought Monitoring in the USAPI}

The small size, tropical climate, and geomorphology of the islands in the USAPI limit the amount and type of data that are available for drought analysis. Daily precipitation is reported at the primary airport and cooperative weather stations, reservoir information is routinely available from Majuro, and anecdotal impacts information is reported. The precipitation falls as rain, never as snow. Some streams on Guam (mainly around Fena Reservoir) have USGS stream gauges, but most streams in the 
USAPI are not instrumented. Streamflow, groundwater gauge, and soil moisture measurements are not available operationally - this information is provided anecdotally. Satellite observations are of limited use-most islands are smaller than the spatial resolution of NDVI products, but satellite-based quantitative precipitation estimates (QPE) from such products as the NASA/NOAA SPoRT (Short-term Prediction Research and Transition Center) QPE can provide synoptic-scale pictures of rainfall amounts over relevant time scales of one, three, and seven days. The SPI is computed on a monthly time scale (for the last 1, 2, 3, 6, 12, 18, and 24 months) for the primary stations, but it is not available near-real time on a weekly basis. Impact information that is routinely reported includes the occurrence and extent of wildfires; subjective observations of stream levels for high islands and reservoir levels for Guam, Yap, and Palau; damage to native agriculture; depletion of rainwater catchment reserves; the failure of groundwater supplies (dew stops forming, clay soils develop large cracks, and, as noted earlier, groundwater can become brackish literally overnight); and, ecosystem damage, including browning of vegetation, such as razor grass, sword grass, and the fern-shrub dicranopteris linearis, and jellyfish kill in Palau's Jellyfish Lake. Precipitation is the main drought indicator. Monthly precipitation normals vary widely from season to season, rendering the percent of normal and SPI less useful as an indicator than they are for the CONUS. ET is high year-round. ENSO is the primary climatic driver.

These data limitations force a minor departure from the traditional USDM convergence of evidence methodology when assessing operational drought in the USAPI. Most islands are dependent on rainfall catchment systems for water supply, and these are able to provide water for approximately two or three weeks with no rainfall before running out, so a dry spell of three weeks can initiate the onset (D0) of a short-term drought. Local knowledge and experience have determined that a weekly minimum of $50.8 \mathrm{~mm}$ (two inches) of rain ( $25.4 \mathrm{~mm}$ (one inch) for the Marianas and American Samoa) is needed to meet most of the water needs in this environment and stave off the development of drought. The corresponding monthly minimum is $203.2 \mathrm{~mm}$ (101.6 mm for the Marianas and American Samoa) (eight (four) inches). Rainfall amounts that are less than the monthly minimum are generally inadequate to replenish home rain catchments and municipal water supplies, or provide for adequate streamflow to refill reservoir catchment systems, while, for amounts less than half of that, threats to agriculture rapidly escalate and the extent and severity of wildfire increases significantly [18]. If an island is in a non-drought or non-abnormal dryness (D-Nothing) status, then rainfall that is equal to or more than this weekly (and monthly) minimum will continue the D-Nothing status. Three consecutive weeks below the weekly precipitation minimum, or two consecutive months below the monthly minimum, is enough to trigger a USDM classification of D0. Once an island enters into a D0 status, the convergence of precipitation percentiles, SPI values, and impacts determines the USDM drought (D1-D4) status.

The traditional USDM maps (50 States and Puerto Rico) are presented as a "page 1" USDM map, while the USAPI are included on a "page 2" USDM map (Figure 1). Draft maps of the USAPI are distributed via email listserv to several dozen local experts who provide feedback, local expertise, and impacts information that modify the drought depiction. Local impact information is also provided via monthly PEAC conference calls. The small size and limited data for the islands in the USAPI require the maps to depict drought as ArcGIS points (dots) that represent the drought status for each respective island, instead of ArcGIS polygons, as shown on the "page 1" map. 


\section{U.S. Affiliated Pacific Islands and U.S. Virgin Islands}

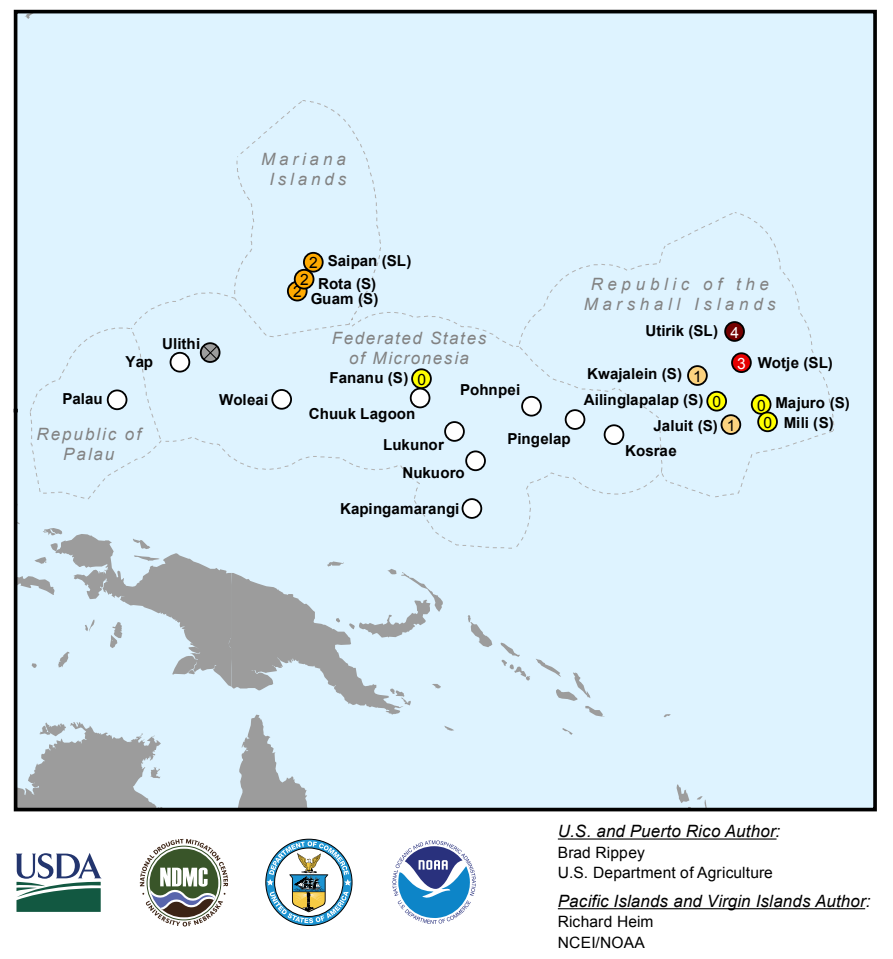

16 June 2019

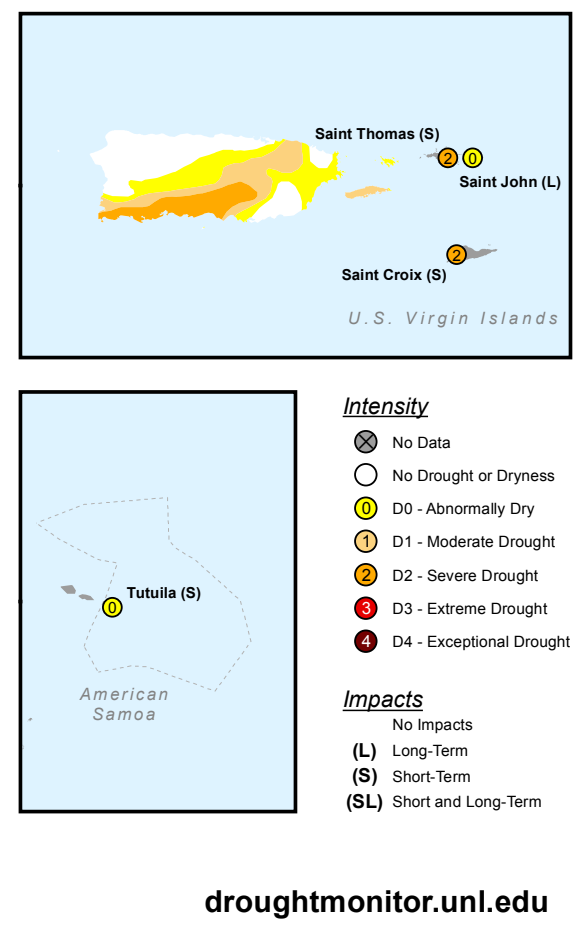

Figure 1. The drought status for the U.S.-Affiliated Pacific Islands (USAPI) (along with the U.S. Virgin Islands) is plotted on a "Page 2" of the USDM map. The drought status is plotted as points (dots) representing the overall conditions across each respective island. (The "Page 1" analysis for Puerto Rico appears in the U.S. Virgin Islands component for completeness.) The USDM maps and data base are maintained online by the National Drought Mitigation Center [22].

\section{Summary and Conclusions}

The USAPI present a unique set of circumstances and conditions for monitoring, and even defining, drought. The USDM "convergence of evidence" methodology for monitoring drought, which works effectively for the CONUS, was modified when applied to the USAPI. The modification was the application of weekly and monthly minimum thresholds for precipitation needed to meet most water needs. Drought is initiated if the weekly or monthly precipitation total is less than the corresponding minimum. The standard USDM "convergence of evidence" process is then applied to the available precipitation and impacts information to determine the severity of the drought. This methodology has worked successfully during the multi-year development of this process and now its incorporation into USDM operational drought monitoring.

This work highlights the development of drought-related tools in locations of data scarcity. The USAPI approach provides a useful framework or guidance for addressing such needs in other data scarce locations, but it is crucial that any application of this framework be tailored to the user needs of the locations.

Use-inspired science and participatory design are important as products and services are developed and enhanced by applying direct knowledge of the subject matter to the final product. User-engagement is a continual process, as the USDM includes a peer-review process in the weekly production of the map analysis and narrative, and biennial USDM Forum workshops solicit recommendations from users and stakeholders regarding ways to improve the product. 
Author Contributions: Conceptualization, R.R.H.J.; formal analysis, R.R.H.J., C.G., M.A.L. and B.B.; investigation, R.R.H.J., C.G. and M.A.L.; methodology, R.R.H.J., C.G. and M.A.L.; Writing-original draft, R.R.H.J. All authors have read and agreed to the published version of the manuscript.

Funding: This research received no external funding.

Conflicts of Interest: The authors declare no conflict of interest.

\section{References}

1. Svoboda, M.; LeComte, D.; Hayes, M.; Heim, R.; Gleason, K.; Angel, J.; Rippey, B.; Tinker, R.; Palecki, M.; Stooksbury, D.; et al. The drought monitor. Bull. Am. Meteor. Soc. 2002, 83, 1181-1190. [CrossRef]

2. Wardlow, B.D.; Hayes, M.J.; Svoboda, M.D.; Tadesse, T.; Smith, K.H. Sharpening the Focus on Drought-New Monitoring and Assessment Tools at the National Drought Mitigation Center. Earthzine. 30 March 2009. Available online: https://earthzine.org/sharpening-the-focus-on-drought-new-monitoring-and-assessmenttools-at-the-national-drought-mitigation-center/ (accessed on 11 May 2020).

3. Heim, R.R., Jr. A review of Twentieth-Century drought indices used in the United States. Bull. Am. Meteor. Soc. 2002, 83, 1149-1165. [CrossRef]

4. NOAA. Strategic Plan: NOAA's National Environmental Satellite, Data, and Information Service. NOAA/NESDIS Rep; 2016. Available online: www.star.nesdis.noaa.gov/star/documents/matrix/NESDIS_ Strategic_Plan_2016.pdf (accessed on 11 May 2020).

5. Norman, D. The Design of Everyday Things; Doubleday: New York, NY, USA, 1988.

6. Schuler, D.; Namioka, A. (Eds.) Participatory Design: Principles and Practices; Lawrence Erlbaum Associates: Hillsdale, NJ, USA, 1993.

7. Abras, C.; Maloney-Krichmar, D.; Preece, J. User-centered design. In Berkshire Encyclopedia of Human-Computer Interaction; Bainbridge, W., Ed.; Sage Publications: Thousand Oaks, CA, USA, 2004; Volume 2, pp. 763-768.

8. Bødker, K.; Kensing, F.; Simonsen, J. Participatory IT Design: Designing for Business and Workplace Realities; MIT Press: Cambridge, MA, USA, 2004.

9. Spinuzzi, C. The methodology of participatory design. Tech. Commun. 2005, 52, 163-174.

10. Oakley, N.S.; Daudert, B. Establishing best practices to improve usefulness and usability of web interfaces providing atmospheric data. Bull. Am. Meteor. Soc. 2016, 97, 263-274. [CrossRef]

11. Kruk, M.C.; Vose, R.; Heim, R.; Arguez, A.; Enloe, J.; Yin, X.; Wallis, T. Drought amelioration: An engagement-to-implementation success story. Bull. Am. Meteor. Soc. 2018, 99, 2457-2462. [CrossRef]

12. Bathke, D.J.; Prendeville, H.R.; Jacobs, A.; Heim, R.; Thoman, R.; Fuchs, B. Defining drought in a temperate rainforest. Bull. Am. Meteor. Soc. 2019, 100, 2665-2668. [CrossRef]

13. University of Maryland. Drought in the U.S. Affiliated Pacific Islands-Climate Change Impacts and Community Resiliency across a Diverse Landscape. University of Maryland Center for Environmental Science, Integration and Application Network Newsletter 617. 2018. Available online: https://ian.umces.edu/ pdfs/ian_newsletter_617.pdf (accessed on 11 May 2020).

14. Anthony, S.S. Drought in the U.S Affiliated Pacific Islands: Impacts to Water Resources. Workshop Report; 2019. Available online: https://www.sciencebase.gov/catalog/item/5cf82192e4b07f02a70465f6 (accessed on 11 May 2020).

15. Borja, J.; Deenik, J.; Frazier, A.; Giardina, C. Drought in the U.S Affiliated Pacific Islands: Impacts to Agriculture. Workshop Report; 2019. Available online: https://www.sciencebase.gov/catalog/item/ 5cf81feee4b07f02a70465e2 (accessed on 11 May 2020).

16. Cordell, S.; Frazier, A.; Trauernicht, C.; Tsang, Y.-P. 2019: Drought in the U.S Affiliated Pacific Islands: Impacts to Ecosystems. Workshop Report. Available online: https://www.sciencebase.gov/catalog/item/ 5cf820c0e4b07f02a70465eb (accessed on 11 May 2020).

17. Fuchs, B.; Heim, R.; Simeral, D. Drought in the U.S. Affiliated Pacific Islands: Drought Monitoring. 2019. Available online: https://www.sciencebase.gov/catalog/item/5cf82308e4b07f02a7046602 (accessed on 11 May 2020).

18. Polhemus, D.A. Drought in the U.S.-Affiliated Pacific Islands: A Multi-Level Assessment; Final Report; U.S. Fish and Wildlife Service Pacific Islands Fish and Wildlife Office: Honolulu, HI, USA, 2017. [CrossRef] 
19. Keener, V.W.; Izuka, S.K.; Anthony, S. 2012 Freshwater and Drought on Pacific Islands. In Chapter 2 (pp. 35-64) in Climate Change and Pacific Islands: Indicators and Impacts; Report for the 2012 Pacific Islands Regional Climate Assessment; Marra, J.J., Keener, V.W., Finucane, M.I., Spooner, D., Smith, M.H., Eds.; Island Press: Washington, DC, USA, 2012.

20. Lander, M.A. Meteorological Factors Associated with Drought on Guam; Technical Report No. 75; Water and Energy Research Institute of the Western Pacific, University of Guam: Mangilao, GU, USA, 1994.

21. Spennemann, D.H.R. Typhoons in Micronesia. A History of Tropical Cyclones and Their Effects until 1914; Division of Historic Preservation: Saipan, Commonwealth of the Northern Mariana Islands, USA, 2004; p. 201. ISBN 1-878453-79-3. [CrossRef]

22. United States Drought Monitor. Available online: https://droughtmonitor.unl.edu/(accessed on 10 May 2020).

C 2020 by the authors. Licensee MDPI, Basel, Switzerland. This article is an open access article distributed under the terms and conditions of the Creative Commons Attribution (CC BY) license (http://creativecommons.org/licenses/by/4.0/). 